\title{
The potential impact of various diagnostic strategies in cases of chronic pain syndromes associated with lumbar spine degeneration
}

This article was published in the following Dove Press journal: Journal of Pain Research

16 April 2013

Number of times this article has been viewed

\section{Andrey Bokov \\ Olga Perlmutter \\ Alexander Aleynik \\ Marina Rasteryaeva \\ Sergey Mlyavykh}

Scientific Research Institute of Traumatology and Orthopedics, Nizhniy Novgorod, Russian Federation
Correspondence: Andrey Bokov Scientific Research Institute of Traumatology and Orthopedics, Verkhnyaya Volzhskaya Naberezhnaya 18, Nizhniy Novgorod 603I55,

Russian Federation

Tel +7 9107985159

Fax +78312787901

Email andrei_bokov@mail.ru
Purpose: To study the possible effects of various diagnostic strategies and the relative contribution of various structures in order to determine the optimal diagnostic strategy in treating patients with noncompressive pain syndromes.

Study design: Prospective, nonrandomized cohort study of 83 consecutive patients with noncompressive pain syndromes resistant to repeated courses of conservative treatment. The follow-up period was 18 months.

Results: Nucleoplasty was effective in cases of discogenic pain; the consequences related to false positive results of the discography were significant. The most specific criterion was $80 \%$ pain relief after facet joint blocks, whereas $50 \%$ pain relief and any subjective pain relief were not associated with a significant increase in the success rate. A considerable rate of false negative results was associated with $80 \%$ pain relief, whereas $50 \%$ pain relief after facet joint blocks showed the optimal ratio of sensitivity and specificity. Facet joint pain was detected in $50.6 \%$ of cases ( $95 \%$ confidence interval $44.1 \%-66.3 \%$ ), discogenic pain in $16.9 \%$ cases $(95 \%$ confidence interval 9.5\%-26.7\%), and sacroiliac joint pain in $7.2 \%$ cases ( $95 \%$ confidence interval $2.7 \%-15 \%$ ). It was impossible to differentiate the main source of pain in $25.3 \%$ of cases.

Conclusion: It is rational to adjust the diagnostic algorithm to the probability of detecting a particular pain source and, in doing so, reduce the number of invasive diagnostic measures to evaluate a pain source. False positive results of diagnostic measures can negatively affect the overall efficacy of a particular technology; therefore, all reasons for the failure should be studied in order to reach an unbiased conclusion. In choosing diagnostic criteria, not only should the success rate of a particular technology be taken into consideration but also the rate of false negative results. Acceptable diagnostic criteria should be based on a rational balance of sensitivity and specificity.

Keywords: diagnostic strategy, lumbar spine, noncompressive pain, sensitivity, specificity

\section{Introduction}

Chronic pain syndromes associated with degenerative diseases of the lumbar spine remain a problem because of the high prevalence of these morbid conditions; pain syndromes without nerve root compression form the majority of cases. ${ }^{1-3}$

It has been reported that target-specific minimally invasive interventions can cause problems due to difficulties in detecting the main source of pain, but are, nevertheless, essential to achieve at least satisfactory results..$^{4-7}$ The classification of pain syndromes, based on the prevalence of axial or leg pain, can complicate the diagnostic process because pseudoradicular complaints could be a component of noncompressive pain syndromes. ${ }^{7-13}$ It is evident that diagnostic interventions should be applied in order to validate the pain source; however, it has been reported that discography could have a significant frequency 
of false positive results. ${ }^{14-16}$ Diagnostic facet joint blocks is a subjective method because of the necessity of using the visual analog scale (VAS) to assess the results. ${ }^{6}$ Furthermore, various authors use different criteria to validate it. ${ }^{17-19}$

Nucleoplasty and radiofrequency facet joint denervation have been reported to be an effective treatment option in cases of noncompressive discogenic pain and facet joint pain, respectively, in both short- and long-term results. ${ }^{18-25}$ In the majority of studies, different pain syndromes have been studied separately with emphasis on the efficiency of the particular treatment modality; however, a particular diagnostic strategy could also influence the frequency of clinically significant results. Furthermore, the reported low frequency of clinically significant results in some studies could reflect the disadvantages of the applied diagnostic algorithm and could be partly relevant to the intervention used. Studying the possible effects of various diagnostic strategies and the relative contribution of various structures could be beneficial in order to determine the optimal diagnostic strategy in treating patients with noncompressive pain syndromes.

\section{Study design}

This study was a prospective, nonrandomized cohort study of 83 patients presenting with a noncompressive pain caused by degenerative processes of the lumbar spine. The participants underwent surgical interventions during the period of March 2009 to October 2010; 25 patients were treated with nucleoplasty and 62 with radiofrequency denervation of facet joints. The results of nucleoplasty were analyzed in 25 participants $(100 \%)$ and the results of radiofrequency denervation of facet joints in 58 cases $(93.5 \%)$. According to the results of diagnostic procedures and minimally invasive interventions, a conclusion was made in regard to the contribution of various structures in pain syndromes associated with the degenerative processes. Also, the impact of the diagnostic strategy on the results of the minimally invasive procedures used was studied.

\section{Inclusion criteria}

Patients that presented with pain syndromes caused by degenerative processes in the lumbar spine (lumbalgia, lumbosciatalgia) were selected for this study using the following selection criteria:

- No evidence of nerve root compression according to the results of physical examination and neuroimaging;

- Patients resistant to at least 1 month of a conservative therapy (including different types of blocks with corticosteroids);
- Pain intensity of no less than 40 on the 100-point VAS and no less than 40 on the Oswestry Disability Index (ODI).

The potential benefits, risks, advantages, and disadvantages were explained, and written informed consent was received from all participants (concerning the applied type of surgery and participation in the study).

\section{Exclusion criteria}

The exclusion criteria were:

- Litigation;

- Uncontrolled psychological disorders;

- Evidence of nerve root compression;

- Evidence of spinal stenosis, infection, and tumors;

- Spinal surgery in anamnesis (any type).

\section{Preprocedural diagnostic evaluation}

Before the interventions, all participants were given a neurological examination. Initially all of them presented with a noncompressive pain pattern; in all cases, they were negative in regard to nerve root tension symptoms and neurological deficit. ${ }^{26}$ All participants were examined preoperatively using the VAS (scale of 0-100 was applied) and ODI questionnaire version 1. ${ }^{27-29}$ All patients underwent magnetic resonance imaging tomography (1,5 T Siemens Magnetom Symphony, Siemens AG Healthcare Sector, Erlangen, Germany). Computer myelography was applied in case of pseudoradicular pain pattern in addition to magnetic resonance imaging to exclude nerve root compression. Discography was utilized to reproduce pain in cases when discogenic origin of pain was suspected. The reproduction of pain was classified as concordant, partly concordant, discordant, and negative; standard technique using lateral extrapedicular approach was applied. ${ }^{30,31}$ Diagnostic facet joint blocks were performed twice in sterile conditions under the guidance of fluoroscopy (General electric OEC 9800 Plus, Van Buren Charter Township, MI, USA) with two different anesthetics of different time action. Needles were introduced using standard landmarks for the medial branch location (junction of the upper border of the transverse process base and the lateral border of the upper articular process base). At least two of the adjacent medial branches - the nerve supply of the supposed source of pain - were blocked on each side. No more than $0.5 \mathrm{~mL}$ of anesthetic was injected to block each medial branch. Different types of anesthetic were used perform diagnostic blocks (novocaine, lidocaine, bupivacaine). The results were classified as any subjective pain relief, at least $50 \%$ pain relief, and at least $80 \%$ pain relief during 
the anesthetic action. Sacroiliac joints blocks were applied to determine the reasons for failure after nucleoplasty and radiofrequency facet joint denervation. Different types of anesthetic were used to perform diagnostic blocks under the control of fluoroscopy using anesthetics of different time action as described by Maigne et al. ${ }^{32}$

\section{Surgical interventions}

Nucleoplasty was performed by several surgeons in sterile conditions under the guidance of fluoroscopy; six channels were created within the disc using a radiofrequency wand (ArthroCare System Controller 2000, ArthroCare Corporation, Austin, TX, USA), applying an ablation and coagulation mode. The surgical technique was standard without acceptance of any variances, as described elsewhere. ${ }^{21,22,33}$

Radiofrequency facet joint denervation was performed by several surgeons in sterile conditions under the guidance of fluoroscopy. Thermal lesions of medial branches were performed using $22 \mathrm{G}$ radiofrequency probes with a $5 \mathrm{~mm}$ active tip (RF Lesion Generator system RFG-3C Plus, Integra Radionics Inc, Burlington, MA, USA). The medial branch lesion was performed on at least two adjacent levels, proven to be the nerve supply of pain source. After the radiofrequency lesioning of medial branches was performed at temperature $80^{\circ} \mathrm{C}$ for 60 seconds. The conventional technique of radiofrequency facet joint denervation has been previously described. ${ }^{18,34}$

\section{Outcome measures}

Participants were examined after 1 month, 3 months, 6 months, 12 months, and 18 months. No less than $50 \%$ pain intensity relief applying the VAS and at least a $40 \%$ decrease in the ODI score were considered to be clinically significant. ${ }^{35,36}$ The 6-month period was the cutoff between long-term and shortterm results for facet joint denervation and 12 months for the nucleoplasty cases. ${ }^{6}$ Facet joint diagnostic blocks and sacroiliac joint blocks were applied postoperatively to determine the reasons for failure after the minimally invasive procedures.

\section{Statistical analysis}

Various statistical criteria were applied for the analysis of data sets. Fisher's exact test was used for dichotomized data sets; if a statistically significant difference was established, the logistic regression analysis was applied (quasi-Newton algorithm). For continuous data sets, the normality test (Shapiro-Wilk test), Wilcoxon test, Kruskal-Wallis test, and Friedman test were used. Statistical power was calculated twice (planning the study and a posteriori) using the Monte
Carlo method (2000 simulations). The Anderson-Darling, Kolmogorov-Smirnov, and Pearson's Chi-squared goodness of fit tests were applied for the distribution fitting of the data sets (required for the statistical power calculation using the Monte Carlo method).

\section{Results}

Prior to treatment, patients presented with noncompressive pain syndromes; in 52 cases there was a domination of axial pain and 31 patients presented with a pseudoradicular syndrome (a prevalence of leg pain; however, the symptoms of nerve root tension were negative and no neurological deficit was evaluated).

In 22 cases, the clinical findings were similar to those described in manuscripts dedicated to the study of facet joint syndrome presentation. ${ }^{37,38}$ The decision to perform radiofrequency facet joint denervation was based on:

- Clinical presentation;

- Evidence of facet joint degeneration from imaging results;

- Reproduction of pain during pain provocation before radiofrequency lesioning.

In 61 cases, the decision to perform discography and diagnostic facet joint blocks was based on:

- Disc height no less than $50 \%$ of normal - discography was applied;

- Negative results of discography - repeated facet joint blocks were administered;

- Disk height loss more than 50\% - repeated facet joint blocks were administered.

Of the discographies performed, only 25 cases experienced a concordant pain reproduction; those patients were treated with nucleoplasty. In 36 cases, repeated facet joint blocks were administered. The results of facet joint blocks were classified as any subjective pain relief, at least $50 \%$ pain relief, and $80 \%$ pain relief according to the results of VAS application. All 36 patients presented with subjective pain relief, but only 26 presented with at least $50 \%$ pain relief and eleven presented with $80 \%$ pain relief. In all cases of subjective pain relief, radiofrequency facet joint denervation was applied. The demographic data are presented in Table 1.

After nucleoplasty, eleven (44\%) patients presented with unsatisfactory results. To find the reasons for nucleoplasty failure, facet joint blocks were applied and nine of the eleven patients experienced at least $80 \%$ pain relief during the time of the anesthetic action, thereafter the hyperdiagnostics of discogenic pain was evident. After the nine patients had been excluded, the results of nucleoplasty were reassessed 
Table I The demographic characteristics of the enrolled patients

\begin{tabular}{lll}
\hline & $\begin{array}{l}\text { RF facet joint denervation without } \\
\text { facet block administration }\end{array}$ & $\begin{array}{l}\text { Minimally invasive procedures performed after } \\
\text { discography and facet joint blocks }\end{array}$ \\
\cline { 2 - 3 } & & Nucleoplasty denervation of facet joints \\
\hline $\mathrm{n}$ & 22 & 25 \\
Female & 16 & 12 \\
Age & $M=51.3812 \pm 2.86 \mid 4$ & $M=43.9600 \pm 2.1404$ \\
& $S D=13.4213$ & $S D=10.7023$ \\
\hline
\end{tabular}

Abbreviations: M, mean; RF, radiofrequency; SD, standard deviation.

and this procedure turned out to be positive in both the short- and long-term. The dynamics of the VAS and the ODI scores are presented in Tables 2-4. After nucleoplasty, statistically significant decreases in pain intensity and pain disability were observed ( $P=0.0006$ and $P=0.0008$, respectively). Throughout the period of observation, no statistically significant changes were observed in pain intensity and pain disability $(P=0.8817$ and $P=0.4813$, respectively; Friedman test). In all cases of clinically significant pain relief, the results were consistent throughout the period of observation.

It is obvious that in a considerable number of cases the results of provocative discography were false positive. Even though the proportion of patients treated with nucleoplasty was low, the negative input of discogenic pain hyperdiagnostics was statistically significant (proportions of clinically significant results were 14/16 versus 14/25 if diagnostic facet blocks were not introduced into the diagnostic algorithm prior to discography; $P=0.0477$ ).

In cases when the decision to apply radiofrequency denervation was based on clinical findings and the results of imaging, the rate of clinically significant results within the first 3 months was only 13 out of 22 . Within 6 months, it was only twelve out of 22 , followed by a further reduction in the number of patients presenting clinically significant results because of medial branch regeneration proven by diagnostic facet joint blocks (Table 5). The reasons for failure were sacroiliac joint pain in one case, complex biomechanical impairment of spinal segments that could not be reduced to the pathology of a particular structure in six cases, and undetermined source of pain in two cases.

The application of facet joint blocks with making diagnostic criteria gradually stricter was analyzed in a group of 36 patients (Table 5). In cases when any subjective pain relief was applied as a diagnostic criterion, the rate of clinically significant results was the same as when there was no application of facet joint blocks. By introducing a restriction ( $50 \%$ pain intensity relief applying VAS), it became possible to exclude ten cases with negative results of facet joint denervation. Further restrictions ( $80 \%$ pain relief applying VAS) resulted in a statistically significant increase in the clinically significant results rate within the first 6 months, but it produced nine false negative results in regard to the prediction of clinically significant results at 12-18 months. This effect is statistically significant (zero false negative results if 50\% pain relief was applied as the criterion versus nine false negative results if $80 \%$ pain relief was applied; $P=0.0012$ for 6-month results).

The regeneration of medial branches within the 6-12month period of observation neglected the estimated differences (the regeneration of medial branches was confirmed by the results of facet joint blocks). The reasons for unsatisfactory results were studied in a group of patients treated with radiofrequency facet joint denervation after application of diagnostic blocks. The sacroiliac joints were the dominant pain source in five cases, the biomechanical impairment of spinal segments in eight cases, and the source of pain was not able to be detected in three cases. It should be mentioned

Table 2 The dynamics of pain intensity and pain disability after nucleoplasty application

\begin{tabular}{lllll}
\hline & $\begin{array}{l}\text { Pain intensity } \\
\text { before nucleoplasty }\end{array}$ & $\begin{array}{l}\text { Pain intensity } \\
\text { I month after } \\
\text { nucleoplasty }\end{array}$ & $\begin{array}{l}\text { Pain disability (ODI) } \\
\text { before nucleoplasty }\end{array}$ & $\begin{array}{l}\text { Pain disability (ODI) } \\
\text { after nucleoplasty }\end{array}$ \\
\hline $\mathrm{N}$ & 16 & 16 & 16 & 16 \\
Mean & 66.3333 & 14.80 & 57.8667 & 13.5333 \\
Median & 60.0 & 10.0 & 58.0 & 12.0 \\
UQ & 70.0 & 20.0 & 68.0 & 16.0 \\
LQ & 50.0 & 0.0 & 46.0 & 0.0 \\
\hline
\end{tabular}

Abbreviations: LQ, lower quartile; ODI, Oswestry Disability Index; UQ, upper quartile. 
Table 3 The dynamics of pain intensity throughout the observation period

\begin{tabular}{llllll}
\hline & I month & $\mathbf{3}$ months & $\mathbf{6}$ months & 12 months & 18 months \\
\hline $\mathrm{N}$ & 16 & 16 & 16 & 16 & 16 \\
Mean & 14.80 & 16.3333 & 15.3333 & 16.0 & 15.6667 \\
Median & 10.0 & 10.0 & 10.0 & 10.0 & 10.0 \\
UQ & 20.0 & 25.0 & 15.0 & 20.0 & 20.0 \\
LQ & 0.0 & 10.0 & 10.0 & 10.0 & 10.0 \\
\hline
\end{tabular}

Abbreviations: LQ, lower quartile; UQ, upper quartile.

that nine patients out of 20 with clinically significant results of facet joint radiofrequency denervation initially presented with a pseudoradicular syndrome (domination of leg pain with lateralization). According to the results, the overall effect of facet joint blocks being introduced into a diagnostic algorithm with the criterion of 50\% pain relief in all cases of noncompressive pain syndromes increased the efficacy of minimally invasive treatment by diminishing the hyperdiagnostics of discogenic pain and the number of cases in which the cause of pain syndrome could be simplified down to the pathology of facet joints only (the rate of clinically significant results was $55.3 \%$ [ $95 \%$ confidence interval $41.1 \%-69.5 \%$ ] if facet joints blocks were not applied versus $84 \%$ [ $95 \%$ confidence interval $74.3 \%-94.2 \%$ ] if applied in all cases of noncompressive pain syndromes; $P=0.0037$, Fisher's exact test).

According to the results of this study, the facet joint was detected as the main source of pain in $50.6 \%$ of cases (95\% confidence interval 44.1\%-66.3\%); discogenic pain in $16.9 \%$ of cases ( $95 \%$ confidence interval $9.5 \%-26.7 \%$ ), and sacroiliac joint pain in $7.2 \%$ cases $(95 \%$ confidence interval $2.7 \%-15.0 \%$ ). It was impossible to differentiate the main source of pain in $25.3 \%$ of cases.

\section{Discussion}

It has been reported that the evaluation of the main pain source in cases of spine degenerative diseases could be associated with certain difficulties. Because of the same segmental innervation, the patterns of pain originating from different structures could bear some resemblance. ${ }^{39-45}$ Furthermore, every movement of the lumbar spine involves all vertebral segments, therefore clinical provocative tests without application of diagnostic interventions can hardly determine the cause of pain syndrome. ${ }^{17,46-48}$ In the current study, it was determined that cases of discogenic pain and facet joint pain could present with a pseudoradicular syndrome that can be misleading in the attempt to evaluate discogenic pain. The significant rate of false positive pain provocations when applying discography could result in a considerable number of diagnostic mistakes and affect the success rate of nucleoplasty. The interference of these errors must be taken into consideration when studying the results of intradiscal interventions in order to make a valid conclusion in regard to the efficacy of the particular intervention used. The results of the current study show that nucleoplasty is effective in cases of noncompressive discogenic pain; however, false positive results of discography could have a negative effect on the results of nucleoplasty. Apparently, because of the attempt to apply a diagnostic algorithm with an emphasis on diagnosing discogenic pain in cases of pseudoradicular pain presentation and because of false positive results of discography, the hyperdiagnostics of discogenic pain could be one of the frequent diagnostic mistakes.

Diagnostic facet joint blocks proved to be the only method that provided a valid conclusion on pain origin; nevertheless, the information concerning the optimal criteria remains controversial. Although $80 \%$ of pain relief after facet joint blocks is recommended as the criterion of facet joint pain diagnosis, some authors apply the criterion of $50 \%$ or $70 \%$ pain relief., ${ }^{4,6,17-19,49}$ Using any pain relief as a criterion of facet joint pain without VAS application, no statistically significant increase in the rate of clinically significant results

Table 4 The Oswestry Disability Index dynamics throughout the observation period

\begin{tabular}{|c|c|c|c|c|c|}
\hline & I month & 3 months & 6 months & 12 months & 18 months \\
\hline $\mathrm{N}$ & 15 & 15 & 15 & 15 & 15 \\
\hline Mean & 13.5333 & 14.9333 & 14.2667 & | 4.2667 & I3.8667 \\
\hline Median & 12.0 & 12.0 & 12.0 & 12.0 & 12.0 \\
\hline UQ & 16.0 & 16.0 & 16.0 & 18.0 & 16.0 \\
\hline LQ & 0.0 & 8.0 & 8.0 & 8.0 & 10.0 \\
\hline
\end{tabular}

Abbreviations: LQ, lower quartile; UQ, upper quartile. 
Table 5 Analysis of the clinically significant results rate after radiofrequency denervation using different diagnostic criteria and significant difference in success rate compared with that registered in cases when diagnostic blocks were not applied

\begin{tabular}{|c|c|c|c|c|c|}
\hline & I month & 3 months & 6 months & 12 months & 18 months \\
\hline $\begin{array}{l}\text { Clinic, imaging, pain provocation } \\
(\mathrm{n}=22)\end{array}$ & I 3 (59\%) & 13 (59\%) & $12(54 \%)$ & $8(36 \%)$ & $4(18 \%)$ \\
\hline Any subjective pain relief & $23(64 \%)$ & $20(55 \%)$ & $20(55 \%)$ & $12(33 \%)$ & $9(25 \%)$ \\
\hline$(n=36)$ & $P=0.784 I$ & $P=0.9999$ & $P=0.9999$ & $P=0.9999$ & $P=0.7475$ \\
\hline $50 \%$ pain relief & $23(88 \%)$ & $20(77 \%)$ & $20(77 \%)$ & 12 (46\%) & $9(35 \%)$ \\
\hline$(n=26)$ & $P=0.0420$ & $P=0.2227$ & $P=0.1310$ & $P=0.565 \mathrm{I}$ & $P=0.3288$ \\
\hline $80 \%$ pain relief & II (I00\%) & II (100\%) & $\mathrm{II}(100 \%)$ & $6(54 \%)$ & $3(27 \%)$ \\
\hline$(n=I I)$ & $P=0.0150$ & $P=0.0150$ & $P=0.0129$ & $P=0.4587$ & $P=0.6610$ \\
\hline
\end{tabular}

was achieved. According to the current results, if an $80 \%$ criterion was applied, a statistically significant increase in the rate of clinically significant results could be achieved, compared with that estimated in the group without facet block application; however, the loss of sensitivity could be another potential effect of this specificity increase. By applying a 50\% pain relief criterion, it became possible to predict the failure of facet joint denervation in ten cases. In addition, no false negative results using this criterion were observed. By making the criterion stricter ( $80 \%$ pain relief), a maximal exclusion of false positive results of diagnostic blocks was achieved, although a considerable number of false negative results was observed in predicting the result of facet joint denervation. It is questionable whether such a tactic is rational in daily practice because the procedure of radiofrequency facet joint denervation was proven to be safe and capable in providing short- and long-term pain relief in cases of pain caused by facet joint degeneration. ${ }^{36,50}$ False negative results could necessitate the application of more aggressive modalities or the elongation of treatment; however, fast recovery could have been achieved with minimally invasive treatment. In other words, false negative results of various diagnostic tools could result in a considerable negative social impact.

Analysis of the main causes of noncompressive pain syndromes reports similar results to previous reports and illustrates that facet joints are the most frequent source of chronic pain syndrome associated with degenerative processes of the lumbar spine. ${ }^{4,51}$ In terms of this specificity, it is rational to adjust the diagnostic strategy to the probability of detecting a particular pain source. Another reason to start off with diagnostic blocks of facet joints in questionable and uncertain situations is that diagnostic and therapeutic procedures in those cases are rarely associated with complications, whereas discography and nucleoplasty could cause spondylodiscitis and it is still debatable whether those procedures could cause further degeneration of the disc. ${ }^{52-56}$
There are some limitations to this study. It could be criticized because it is nonrandomized. Its fusion of a population study, efficacy of diagnostic measures, and assessment of interventions could be considered a weak point; however, this design could be beneficial in disclosing the additional significant effects that could be important in daily practice.

\section{Conclusion}

It is rational to adjust the diagnostic algorithm to the probability of detecting a particular pain source and, in doing so, reduce the number of invasive diagnostic measures to evaluate a pain source. False positive results of diagnostic measures can negatively affect the overall efficacy of a particular technology; therefore, all reasons for the failure should be studied in order to provide an unbiased conclusion. In choosing diagnostic criteria, not only should the success rate of a particular technology be taken into consideration but also the rate of false negative results. Acceptable diagnostic criteria should be based on a rational balance of sensitivity and specificity.

\section{Disclosure}

The authors report no conflicts of interest in this work.

\section{References}

1. Manchikanti L, Singh V, Datta S, Cohen SP, Hirsch JA. Comprehensive review of epidemiology, scope, and impact of spinal pain. Pain Physician. 2009;12(4):E35-E70.

2. Licciardone JC. The epidemiology and medical management of low back pain during ambulatory medical care visits in the United States. Osteopath Med Prim Care. 2008;2:11.

3. Pang WW, Mok MS, Lin ML, Chang DP, Hwang MH. Application of spinal pain mapping in the diagnosis of low back pain - analysis of 104 cases. Acta Anaesthesiol Sin. 1998;36(2):71-74.

4. Manchikanti L, Boswell MV, Singh V, et al. Comprehensive review of neurophysiologic basis and diagnostic interventions in managing chronic spinal pain. Pain Physician. 2009;12(4):E71-E120.

5. Manchikanti L, Boswell MV, Datta S, et al. Comprehensive review of therapeutic interventions in managing chronic spinal pain. Pain Physician. 2009;12(4):E123-E198.

6. Manchikanti L, Boswell MV, Singh V, et al. Comprehensive evidencebased guidelines for interventional techniques in the management of chronic spinal pain. Pain Physician. 2009;12(4):699-802. 
7. Markwalder TM, Merat M. The lumbar and lumbosacral facetsyndrome. Diagnostic measures, surgical treatment and results in 119 patients. Acta Neurochir (Wien). 1994;128(1-4):40-46.

8. Freynhagen R, Rolke R, Baron R, et al. Pseudoradicular and radicular lowback pain - a disease continuum rather than different entities? Answers from quantitative sensory testing. Pain. 2008;135(1-2):65-74.

9. Kallewaard JW, Terheggen MA, Groen GJ, et al. Discogenic low back pain. Pain Pract. 2010;10(6):560-579.

10. Galm R, Frohling M, Rittmeister M, Schmitt E. Sacroiliac joint dysfunction in patients with imaging-proven lumbar disc herniation. Eur Spine J. 1998;7(6):450-453.

11. Milette PC, Fontaine S, Lepanto L, Breton G. Radiating pain to the lower extremities caused by lumbar disk rupture without spinal nerve root involvement. AJNR Am J Neuroradiol. 1995;16(8):1605-1613.

12. Mooney V, Robertson J. The facet syndrome. Clin Orthop Relat Res. 1976;115:149-156.

13. Fairbank JC, Park WM, McCall IW, O’Brien JP. Apophyseal injection of local anesthetic as a diagnostic aid in primary low-back pain syndromes. Spine (Phila Pa 1976). 1981;6(6):598-605.

14. Carragee EJ, Alamin TF, Carragee JM. Low-pressure positive discography in subjects asymptomatic of significant low back pain illness. Spine (Phila Pa 1976). 2006;31(5):505-509.

15. Carragee EJ, Lincoln T, Parmar VS, Alamin T. A gold standard evaluation of the "discogenic pain" diagnosis as determined by provocative discography. Spine (Phila Pa 1976). 2006;31(18):2115-2123.

16. Carragee EJ, Alamin TF, Miller J, Grafe M. Provocative discography in volunteer subjects with mild persistent low back pain. Spine J. 2002;2(1):25-34.

17. Schwarzer AC, Aprill CN, Derby R, Fortin J, Kine G, Bogduk N. Clinical features of patients with pain stemming from the lumbar zygapophyseal joints. Is the lumbar facet syndrome a clinical entity? Spine (Phila Pa 1976). 1994;19(10):1132-1137.

18. Gofeld M, Jitendra J, Faclier G. Radiofrequency denervation of the lumbar zygapophysial joints: 10-year prospective clinical audit. Pain Physician. 2007;10(2):291-300.

19. Nath S, Nath CA, Pettersson K. Percutaneous lumbar zygapophysial (facet) joint neurotomy using radiofrequency current, in the management of chronic low back pain: a randomized double-blind trial. Spine (Phila Pa 1976). 2008;33(12):1291-1297.

20. Singh V, Piryani C, Liao K. Role of percutaneous disc decompression using coblation in managing chronic discogenic low back pain: a prospective, observational study. Pain Physician. 2004;7(4):419-425.

21. Singh V, Piryani C, Liao K, Nieschulz S. Percutaneous disc decompression using coblation (nucleoplasty) in the treatment of chronic discogenic pain. Pain Physician. 2002;5(3):250-259.

22. Sharps LS, Isaac Z. Percutaneous disc decompression using nucleoplasty. Pain Physician. 2002;5(2):121-126.

23. Masala S, Massari F, Fabiano S, et al. Nucleoplasty in the treatment of lumbar diskogenic back pain: one year follow-up. Cardiovasc Intervent Radiol. 2007;30(3):426-432.

24. Reddy AS, Loh S, Cutts J, Rachlin J, Hirsch JA. New approach to the management of acute disc herniation. Pain Physician. 2005; 8(4):385-390.

25. Dreyfuss P, Halbrook B, Pauza K, Joshi A, McLarty J, Bogduk N. Efficacy and validity of radiofrequency neurotomy for chronic lumbar zygapophysial joint pain. Spine (Phila Pa 1976). 2000;25(10):1270-1277.

26. Manchikanti L, Singh V, Bakhit CE, Fellows B. Interventional techniques in the management of chronic pain: part 1.0. Pain Physician. 2000;3(1):7-42.

27. Gould D, Kelly D, Goldstone L, Gammon J. Examining the validity of pressure ulcer risk assessment scales: developing and using illustrated patient simulations to collect the data. J Clin Nurs. 2001;10(5):697-706.

28. Wewers ME, Lowe NK. A critical review of visual analogue scales in the measurement of clinical phenomena. Res Nurs Health. 1990; 13(4):227-236.

29. Fairbank JC, Pynsent PB. The Oswestry Disability Index. Spine (Phila Pa 1976). 2000;25(22):2940-2952.
30. Fortin JD. Precision diagnostic disc injections. Pain Physician. 2000;3(3):271-288.

31. Tomecek FJ, Anthony CS, Boxell C, Warren J. Discography interpretation and techniques in the lumbar spine. Neurosurg Focus. 2002;13(2):E13.

32. Maigne JY, Aivaliklis A, Pfefer F. Results of sacroiliac joint double block and value of sacroiliac pain provocation tests in 54 patients with low back pain. Spine (Phila Pa 1976). 1996;21(16):1889-1892.

33. Singh V, Piryani C, Liao K. Evaluation of percutaneous disc decompression using coblation in chronic back pain with or without leg pain. Pain Physician. 2003;6(3):273-280.

34. Windsor RE. Radiofrequency lumbar zygapophysial (facet) joint denervation: a preliminary report of a new concept. Pain Physician. 2003;6(1):119-123.

35. Manchikanti L, Derby R, Benyamin RM, Helm S, Hirsch JA. A systematic review of mechanical lumbar disc decompression with nucleoplasty. Pain Physician. 2009;12(3):561-572.

36. Boswell MV, Colson JD, Sehgal N, Dunbar EE, Epter R. A systematic review of therapeutic facet joint interventions in chronic spinal pain. Pain Physician. 2007;10(1):229-253.

37. Young S, Aprill C, Laslett M. Correlation of clinical examination characteristics with three sources of chronic low back pain. Spine J. 2003;3(6):460-465.

38. Lippitt AB. The facet joint and its role in spine pain. Management with facet joint injections. Spine (Phila Pa 1976). 1984;9(7):746-750.

39. Forst SL, Wheeler MT, Fortin JD, Vilensky JA. The sacroiliac joint: anatomy, physiology and clinical significance. Pain Physician. 2006;9(1):61-67.

40. Bogduk N, Tynan W, Wilson AS. The nerve supply to the human lumbar intervertebral discs. J Anat. 1981;132(Pt 1):39-56.

41. Bogduk N, Wilson AS, Tynan W. The human lumbar dorsal rami. J Anat. 1982;134(Pt 2):383-397.

42. Suseki K, Takahashi Y, Takahashi K, Chiba T, Yamagata M, Moriya H. Sensory nerve fibres from lumbar intervertebral discs pass through rami communicantes. A possible pathway for discogenic low back pain. J Bone Joint Surg Br. 1998;80(4):737-742.

43. Richardson J, Collinghan N, Scally AJ, Gupta S. Bilateral L1 and L2 dorsal root ganglion blocks for discogenic low-back pain. BrJAnaesth. 2009;103(3):416-419.

44. Takahashi K, Aoki Y, Ohtori S. Resolving discogenic pain. Eur Spine J. 2008;17(Suppl 4):428-431.

45. Suseki K, Takahashi Y, Takahashi K, et al. Innervation of the lumbar facet joints. Origins and functions. Spine (Phila Pa 1976). 1997;22(5): 477-485.

46. Schwarzer AC, Derby R, Aprill CN, Fortin J, Kine G, Bogduk N. Pain from the lumbar zygapophysial joints: a test of two models. J Spinal Disord. 1994;7(4):331-336.

47. Schwarzer AC, Wang SC, Bogduk N, McNaught PJ, Laurent R. Prevalence and clinical features of lumbar zygapophyseal joint pain: a study in an Australian population with chronic low back pain. Ann Rheum Dis. 1995;54(2):100-106.

48. Manchikanti L, Pampati V, Fellows B, Baha AG. The inability of the clinical picture to characterize pain from facet joints. Pain Physician. 2000;3(2):158-166

49. Manchikanti L, Pampati S, Cash KA. Making sense of the accuracy of diagnostic lumbar facet joint nerve blocks: an assessment of the implications of $50 \%$ relief, $80 \%$ relief, single block, or controlled diagnostic blocks. Pain Physician. 2010;13(2):133-143.

50. Kornick C, Kramarich SS, Lamer TJ, Todd Sitzman B. Complications of lumbar facet radiofrequency denervation. Spine (Phila Pa 1976). 2004;29(12):1352-1354.

51. Manchikanti L, Singh V, Pampati V, et al. Evaluation of the relative contributions of various structures in chronic low back pain. Pain Physician. 2001;4(4):308-316.

52. Gruber HE, Rhyne AL 3rd, Hansen KJ, et al. Deleterious effects of discography radiocontrast solution on human annulus cell in vitro: changes in cell viability, proliferation, and apoptosis in exposed cells. Spine J. 2012;12(4):329-335. 
53. Carragee EJ, Don AS, Hurwitz EL, Cuellar JM, Carrino JA, Herzog R. 2009 ISSLS prize winner: does discography cause accelerated progression of degeneration changes in the lumbar disc: a ten-year matched cohort study. Spine (Phila Pa 1976). 2009;34(21):2338-2345.

54. Quero L, Klawitter M, Nerlich AG, Leonardi M, Boos N, Wuertz K. Bupivacaine - the deadly friend of intervertebral disc cells? Spine J. 2011;11(1):46-53.
55. Cuellar VG, Cuellar JM, Vaccaro AR, Carragee EJ, Scuderi GJ. Accelerated degeneration after failed cervical and lumbar nucleoplasty. J Spinal Disord Tech. 2010;23(8):521-524.

56. Osti OL, Fraser RD, Vernon-Roberts B. Discitis after discography. The role of prophylactic antibiotics. J Bone Joint Surg Br. 1990; 72(2):271-274.

\section{Publish your work in this journal}

The Journal of Pain Research is an international, peer-reviewed, open access, online journal that welcomes laboratory and clinical findings in the fields of pain research and the prevention and management of pain. Original research, reviews, symposium reports, hypothesis formation and commentaries are all considered for publication.

\section{Dovepress}

The manuscript management system is completely online and includes a very quick and fair peer-review system, which is all easy to use. Visit http://www.dovepress.com/testimonials.php to read real quotes from published authors. 